AN INVESTIGATION INTO PRACTICAL EXPERIENCES AS

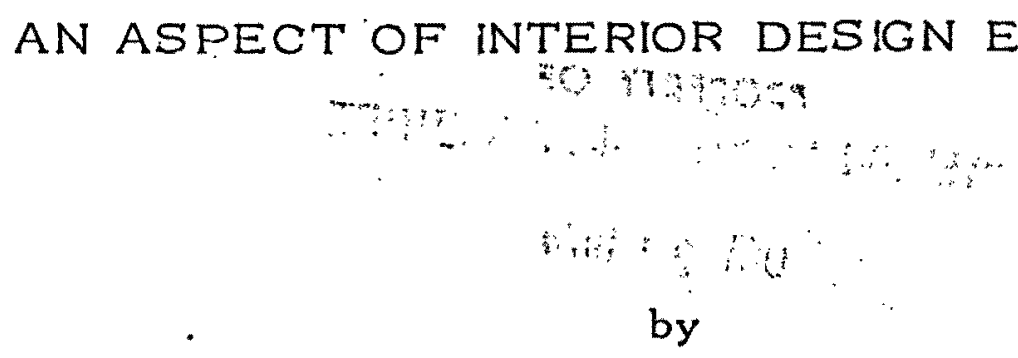

WILLIAM W.KILBORN, I.D.O., S.W.A.

An Advanced Design Project

Submitted to the Faculty of "Undergraduate Studies Through the Department of Interior Design in Partial Fulfillment of the Requirements for the Degree of Bachelor of Applied Arts at Ryerson Polytechnical Institute

\title{
BOOK I
}

Toronto, Ontario, Canada.

$$
1972-73
$$




$$
3^{019^{2}}
$$
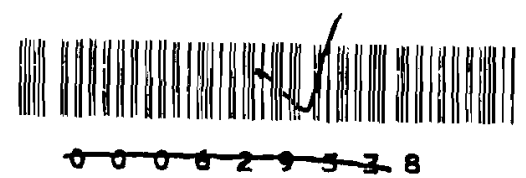

NK2116.4.K5

$\begin{array}{lllllll}0 & 3 & 9 & 4 & 9 & 8 & 5\end{array}$

APPROVED BY:

PROPERTY UT

RYERSOH FOL TIECUNICAL INSTITUTR

$$
301-921-442
$$




\section{PREFACE}

The author wishes to express his gratitude and appreciation to Professor Larry Gray under whose direction the present research was conducted. His willingness to give of his time and knowledge made the carrying out of the research much less burdensome than it might have been. Grateful appreciation is also extended to George Sanders for his help and constructive criticism which he made available to the author throughout the course of the experiments. 
TABLE OF CONTENTS

BOOK I

Page

PREFACE.

LIST OF TABLES ....................... (v)

Chapter

I

INTRODUCTION

Purpose of Present Research...............

II METHOD

Subjects.......................15

Procedures...........................

III RESULTS

Otis $1 . Q$. Test........................

Space Relations Test....................19

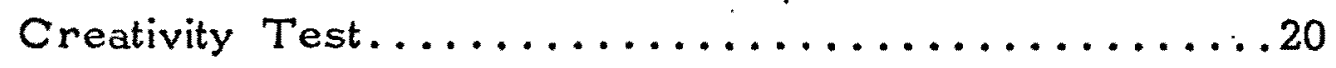

IV MAJOR METHODS \& BALANCE OF PROGRAMME ...25

$\mathrm{V}$ RECOMMENDATIONS..................... 44

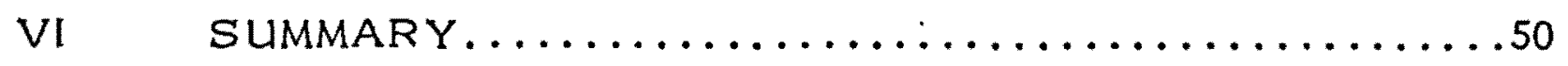

BIBLIOGRAPHY.......................

VITA AUCTORIS................... 52

APPENDIX BOOK $I I \ldots \ldots \ldots \ldots \ldots \ldots \ldots \ldots \ldots \ldots \ldots$ (vi) 


\section{LIST OF TABLES}

\section{TABLES CHAPTER I}

Figure A-A Co-Operative Double Streaming..................l

1. Percentage of Graduates to U.S.Employment............... 12

2. All Engineering Graduates $u$. of $w \ldots \ldots \ldots \ldots \ldots \ldots \ldots \ldots$

3. All Co-Op Engineering Graduates $u$. of $W \ldots \ldots \ldots \ldots \ldots \ldots \ldots$

\section{TABLES CHAPTER III}

1. Analysis of Variances in Test Subjects on Otis Quick-Scoring Mental Ability Test by Arthur S.Otis, Ph.D. - Gama Test-Form C...............18

2. Analy sis of Variance of the Means of 'Total Responses to Differential Aptitude Test Booklet 2 - Form L, Space Relations.................... 19

3. Analysis of Variance of the Means of Total Responses to Creativity Test, Partially adapted from 0.C.A.Entrance Test.........................20

4. Comparisons of Means of the Generalization Gradients..................................... I

\section{TABLES CHAPTER IV}

1. Analysis of Variance for Means of Test Scores by

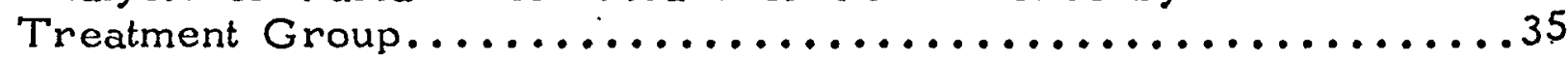

2. Analysis of Variance of the Means of Total Responses to Experimental Test Part I, II, and IV....................

3 (A) Comparison of the Means of the Generalization Gradients to Part III - Creativity...............................

3(B) Analysis of Variance of the Mean Rank for the

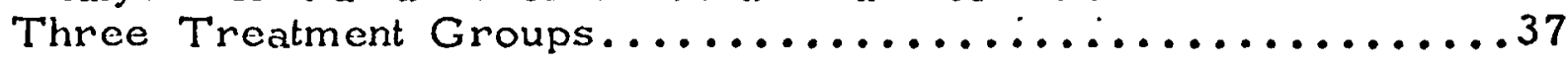

4. Comparison of the Means Average Course Assessment between Fall \& Winter Terms..................... 


\section{CHAPTER I \\ INTRODUCTION}

\section{PURPOSE OF PRESENT RESEARCH}

The purpose of the present study is to discover whether an Interior Design student exposed to practical design experience during his formal education might possibly have an advantage over, (1) the student with educational training only; or (2) the designer with a minimum amount of practical experience and incomplete design education - in terms of problem solving, and academic performance.

The hypotheses are as follows:

A) An experimental group of design students exposed to practical experience will score higher marks on a problem solving test than two control groups: students without practical experience, and outside designers with a maximum of three years experience and no formal design training.

B) The academic standing of the experimental group will not deteriorate compared to the academic standing of the student control group.

The significance of such a study is perhaps more suitably discussed in the light of some general background information concerning related research in the field of engineering and some of the relevant variables collected during January and February 1973.

\section{BACKGROUND OF RELATED RESEARCH}

In view of my hypotheses, I found it necessary to draw an analogy for the purpose of qualifying these experiments.

Engineering students at the University of Waterloo were the subjects found to be most compatible to Interior Design students functions. These students alternate periods of study on campus with periods of work in industry. The success of this programme is indicated by the increase in the participants from 79 students and no employers in 1957 to over 2700 students and 600 employers in 1969. 


\section{BACKGROUND OF RELATED RESEARCH (continued)}

In fact, about 10 percent of all university engineering students in Canada are now enrolled at Waterloo! Additional co-operative programmes have been set up since 1969 in the disciplines of Architecture, Applied Arts, Applied Physics, Applied Psychology, Mathematics, Recreation and Kinesiology.

(1). What is co-operative education? (2) What has made it so popular? (3) Why is the University of Waterloo the only university pledged to a professional use of this system in our Ontario Educational Programme? In answer to the first question (1), the co-operative engineering undergraduate programme is so arranged that the academic programme is combined with relevant work experience in alternating terms, thus enabling the academic terms to be devoted to fundamental and theoretical studies. The programme consists of eight four-month academic terms and six fourmonth work terms, with the practical industrial experience acting as a complement to the academic studies; and assisting in the effective preparation of the students for the engineering profession. The work-study sequence provided in the course is arranged as shown in Figure A-A.

All Year 1 students enroll in September. These Year 1 students spend the first term together at the University, and, as indicated on the diagram, also complete the course and graduate together. Between the first and

1 E.L.Homes, "Co-Op Engineering Education", International Journal of Electrical Engineering Education, 1968. Pg.l 


\section{BACKGROUND OF RELATED RESEARCH (continued)}

last terms, the diagram shows that each class is split into two approximately equal groups (streams) for continuity of employment opportunity on the co-operative programme. Both groups, of course, have the same total time on campus and in industry; one group having a double academic term at the start of the course and the other having a double academic term at the end of the course. The division at the end of the first term of study is based upon student preference, financial considerations of students, etc.

The necessary arrangements for the integration of the work terms, the securing of potential employers of the students, the arranging of interviews, the professional guidance involved, the grading of work reports and generally the whole management of the co-operative employment scheme is handled by a special department of the University - The Department of Co-Ordination and Placement. Members of this Department, called co-ordinators, counsel the students, visit them on their work assignments and introduce the students to the necessary discipline of work and responsibility. The co-ordinators are responsible for ensuring that the work is relevant to the education and development of the student. Relevance in this context does not imply that it must be linked closely to the academic programme but rather that it is challenging to the student.

The University employs sufficient professional personnel plus supporting secretarial and service staff to handle this aspect of the cooperative engineering programme. All co-ordinators are experienced professional engineers. Each co-ordinator is responsible for a maximum 


\section{BACKGROUND OF RELATED RESEARCH (continued)}

of 75 students out in the field at any one time.

Students and employers choose each other through the Co-Ordination Department's placement process. Interviews are arranged on campus; prospective employers list the students they would like to have and the students do likewise. The matching-up is then done in the Computer Centre of the University. This system appears to be very acceptable to both employers and students. The results of the computer sort however, are not binding on employer or student and some rearrangements can always be made.

Satisfactory co-operative work assignments are a prerequisite of graduation and poor performance is thoroughly investigated. No student may continue in a co-operative course if he is not capable of acceptable progress and conduct in his work assignments, and if the "work reports" required for these assignments are unsatisfactory.

The University has an Industrial Advisory Council composed of delegates from companies interested in engineering education. This body acts in an advisory capacity presenting industries' viewpoint to the University .

In answer to the second question, the growth and popularity of the programme can be attributed to several factors: Advantages to Industry:

(i) The engineering student can perform many engineering functions which will relieve or assist the graduate engineer. 


\section{BACKGROUND OF RELATED RESEARCH (continued)}

Advantages to Industry: (continued)

(ii)

The engineering student can be assigned short term projects where it would be uneconomical to hire a graduate on a temporary basis .

(iii) The student can be utilized to carry out engineering functions during periods of peak loads.

(iv) The student under the direction of the engineer can carry out many investigations that are costly under normal methods, such as research consultants for time studies, equipment and building maintenance, flow charts, and checking suppliers of necessary equipment, etc.

(v) The student can function as an inspector or supervisor on construction jobs, road building, traffic control, etc.

(vi) The co-operative programme offers the company an opportunity to evaluate the ability and suitability of the student as a potential permanent employee.

(vii) The co-operative programme offers industry year-round student assistance.

By becoming a Co-operative Company, the firm projects an image to a large segment of the engineering profession of tomorrow. ${ }^{2}$

2 R.J.Weiser, Advantages of The Co-Operative Engineering Programme at the University of Waterloo For You The Employer 1971, Published U. of W., Pamphlet. 


\section{BACKGROUND OF RELATED RESEARCH (continued) -}

Advantages to Students:

For engineering students, the co-operative programme when properly managed appears to have particular appeal, and the growth in the enrollment at Waterloo indicates that the students see distinct advantages in the programme. A comprehensive general review of co-operative programmes was prepared in 1961 under the auspices of the Ford and Edison

Foundation. In this study, the advantages claimed for the co-operative system in the United States were listed as follows:

(i) Students in co-operative programmes find greater meaning in their studies.

(ii) Co-ordination of work and study increases student motivation and purpose.

(iii) Co-operative experience helps students become mature and independent.

(iv) Students develop greater skills in human relations and there is a tendency to break down the segregation of college students into a wholly adolescent community.

(v) Students are helped to relate to the world of work and to test their aptitudes.

(vi) Some able students are encouraged to pursue higher education who would not otherwise have done so or have been able to do so. 
BACKGROUND OF RELATED RESEARCH (continued)

The experience to date of the Faculty of Engineering at Waterloo would be to support all these claimed advantages. However, the same study identified possible disadvantages of the co-operative system as practised in the United States:

(i) That the repeated work-study sequence would lead to confusion of the student.

(ii) That co-operative students could not or would not participate in extracurricular activity.

(iii) That an extra year is required to complete the usual undergraduate activity.

(iv) That much more planning and organizational work is required of the university.

(v) That the co-operative programmes are sensitive to curtailment of employment in periods of economic distress.

However, in the United States it appeared that there were in actual fact no distinguishable differences between students in co-operative engineering programmes and those in conventional engineering programmes as regards items (i) and (ii). The advantages appear to outweigh the disadvantages of (iii) and (iv).

It is interesting to note the impact the co-operative system has on the students. It appears to give the $m$ an awareness of and confidence in the opportunities wilhin Canadian industry and very few are lured by the tempting offers from the United States as can be seen in Table I. 


\section{BACKGROUND OF RELATED RESEARCH (continued)}

Table II shows the number of graduates entering industry and the number proceeding to post graduate study. From Table III it can be seen that on the average over $85 \%$ of the Waterloo graduates entering industry proceed to employment with companies involved in the co-operative programme.

It should be noted that many of the leading engineering schools in the United States offer a co-operative programme in conjunction with a conventional programme and the requirements that only students with high academic standing may enter the co-operative stream. ${ }^{3}$

Why is the University of Waterloo the only university pledged to a use of this system in our Ontario Educational Programme? Perhaps the answer partially lies in the following facts and general information collected from D.H.Copp, Assistant Director Engineering Faculty Liaison: "In the matter of current statistics for 1972 (it is too early to know. what 1973 will show), the number of graduates increased to 424 and the percentage distribution has changed significantly since the 1968 figures shown in Dr.E.L.Homes' report.

Post graduate studies represent about $10 \%$, and the miscellaneous now runs at $4 \%$. Co-operative employers still have the lion's share, $75 \%$ of the grads., with about $11 \%$ hired by non-co-operative employers.

In the matter of starting salaries, the premium paid to the 1972 grads range between $\$ 300$ and $\$ 600$ per year over that offered the graduates of a conventional programme."

3

E.L.Homes, "Op. Sit." Pgs. 6-9 


\section{BACKGROUND OF RELATED RESEARCH (continued)}

The foregoing quotation was taken from a letter sent to me February $6 / 73$ after a series of interviews made by this author during January and February 1973, with University of Waterloo Staff and Student faculty.

My deep appreciation for co-operation goes to the following men:

Dr.A.N.Sherbourne - Dean of Engineering

Dr.T.Morris.Frazier - Chairman - Department of Systems Design Professor George Soulis - Department of Systems Design Mr.D.H.Copp, P.Eng., - Assistant Director, Engineering Faculty Liaison Department of Co-Ordination.

The one major statistic that was unavailable and generally difficult to to establish had to do with comparative job success of Uhiversity of Waterloo students in competition with other universities. Neither the University of Toronto nor the 'Professional Engineering Society' were willing to admit or give me said statistics on first year graduates' success in finding full-time employment. The only, and most significant figures in this regard were verbal and given by Mr.J.St.John, P.Eng., graduating class of 1970-71, University of Waterloo, now employed by Canadian Standards Association, who stated that:

$55 \%$ of the class of 71 were unemployed after six months from graduation. $85 \%$ of the class with employment were hired by Co-Operative employers. Most co-operative students stay with their initial employers longer than students from standard engineering courses.

The qualification for these facts was a poll taken by a class representative of all class members and their employers, for the purpose of an annual graduation dinner. 


\section{BACKGROUND OF RELATED RESEARCH (continued)}

It therefore would appear, until a thorough study proves otherwise, that there is in initial employment no significant advantage for co-operative engineering graduates versus standard graduates from other Ontario institutions unless they are hired from within the Co-operative employer programme. The significance of this study however, still strongly suggests a need for some type of co-related educational and industrial programme for students connected to technological and scientific disciplines. Therefore with this in mind, I set about to discover on a more diminutive scale whether a similar programme can work for Interior Designers. 
1968

1969

1970

Fall Winter Spring Fall Winter Spring Fall

Stream First Second Work Third Work Fourth Work

"A" Term Term Period Term Period Term Period

Stream First Work Second Work. Third Work Fourth

"B"

Term Period Term Period Term Period Term

1971

1972

1973

Winter Spring Fall Winter Spring Fall Winter

Stream Fifth Work Sixth Work Seventh Work Eighth

"A" Term Period Term Period Term Period Term

Stream Work Fifth Work Sixth Work Seventh Eighth

"B" Period Term Period Term. Period Term Term

FIGURE A-A 
PERCENTAGE OF GRADUATES (B.A.Sc.'s) TO INDUSTRIAL EMPLOYMENT IN UNITED STATES

First Graduates 1962

$$
3.0
$$

1963

0

1964

0

1965

1.0

1966

1.4

1967

0

1968

0.5

All years

0.7

TABLE I 
ALL ENGINEERING GRADUATES (B.A.Sc.)

UNIVERSITY OF WATERLOO

\section{Destination of all Graduates with Bachelors Degrees}

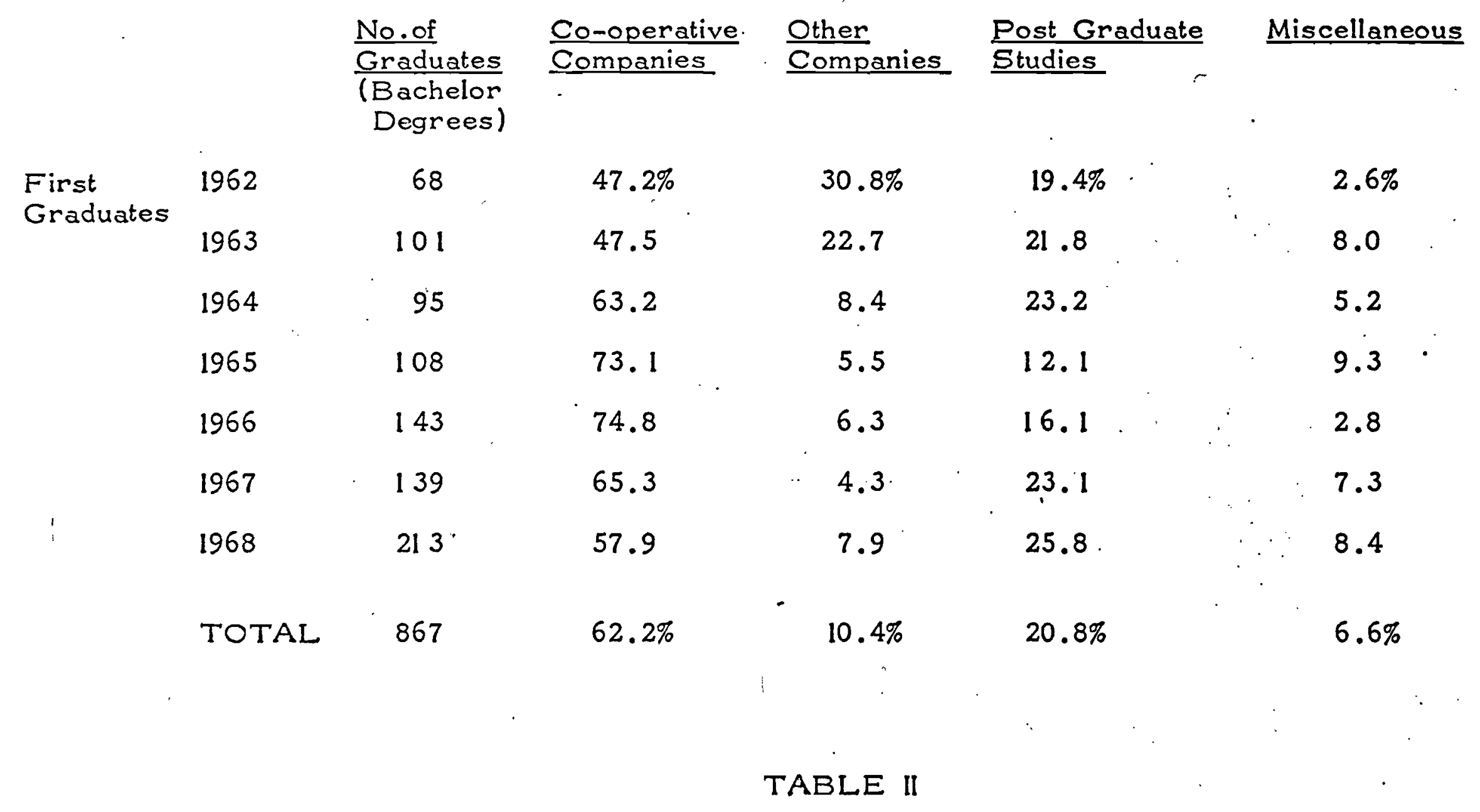


ENGINEERING GRADUATES (B.A.Sc.) TO INDUSTRY

\section{UNIVERSITY OF WATERLOO}

( Co-Operative Engineering Programme

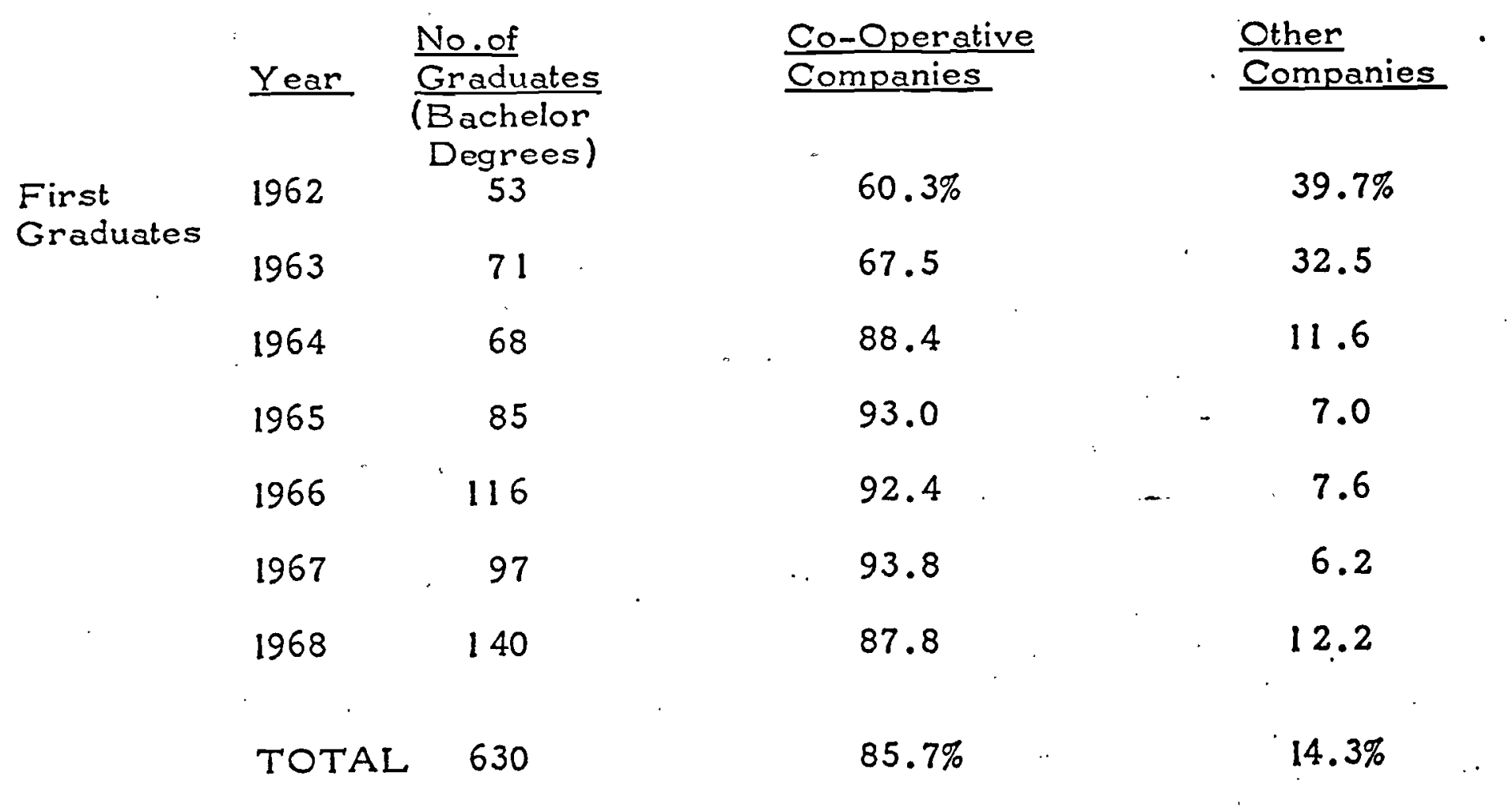

TABLE III 


\section{CHAPTER ॥}

\section{METHOD}

\section{SUBJECTS}

The subjects chosen to arrive at a student experimental and control group were four males and twelve females from third year Interior Design with an age range of 21 to 34 . This group were the majority of a third year Business Practice course, selected because they approximated the experience of our projected requirements for a secondary control group i.e. designers with a minimum amount of practical experience and incomplete design education.

Subjects were asked to complete a series of three tests which totalled a period of an hour and twenty-five minutes, during a randomly selected business practice class which meet Thursday mornings during the Fall Semester of 1972. The purpose of the test was to arrive at a control group and an experimental group consisting of four subjects each. The subjects were neither informed nor made aware of the purpose of the tests at the time. The experimental subjects have now been informed that they were involved in a special programme.

All subjects were given a blank envelope containing a form to be filled in which required their name, student number, and date; they were then told to use the subject number listed on the form as identification on all subsequent test material; after filling in the form, they were told to replace it in the blank envelope, which was then to be sealed.

This procedure guaranteed that evaluators of the tests and the author would make their assessments under completely unbiased conditions. 


\section{SUBJECTS (continued)}

In addition, it acted as protection for the students in all their future assessments by the teaching staff while at this institute, as the student names will not be mentioned in this study, and will be available only through official school records.

\section{PROCEDURES}

Preliminary Experiment - For the purpose of arriving at control and experimental groups, sixteen students took an Otis 1.Q.Test, a Creativity Test, and a Space Relations Test. The three scores, equally weighted, were combined to form one score. The eight students closest to the median (4 above and 4 below) were subjects for the experiment. All tests except the Creativity Test are standard approved tests for psychological and aesthetic evaluation of subjects in use by many institutions for the past ten years.* The Creativity Test as modified by the author, had been in use at the Ontario College of Art as part of an entrance evaluation between the years 1960-1970. Test evaluation was completed by the following Ryerson Instructors, not by the author, prior to computer programming the results:

Professor Larry Gray - Otis 1.Q. Test

Professor George Sanders - Space Relations Test Mr.A.Vasilevich - Creativity Test.

The eight subjects were then randomly distributed to experimental and control conditions for further experimentation. The four experimental subjects received practical experience during January, February and March 1973, while the four control subjects continued with their normal course of studies.

Ron Taber, Ryerson Counselling Department, October 1972. 


\section{PROCEDURES (continued)}

Major Experiment - Experimental and control subjects along with four selected outside subjects having the qualifications required for the aforementioned secondary control group took an unannounced problem solving test. This was conducted under the same conditions as the preliminary experiment, so that the control subjects did not know that they had been singled out from the balance of the class. The test was constructed by a Faculty Member independent of the experimentor. This test was completed during the latter week of March 1973. Post-experimental academic standing for control and experimental subjects was compared to pre-experimental standings during April 1973.

Dependent Analysis - The dependent factors of 1) problem solving and 2) academic performance for all subjects, was then analyzed by the computer; and a comparison of means of the generalization gradients told the author whether this project had any consequential significance in relation to the hypotheses formed. 
CHAPTER III

RESULTS

TABLE I

Analysis of Variance of the Means of the Generalization Gradients for Mental Ability - I.Q. Gama Test - Otis

Scores $118,102,98,129,103,105,121,127,123,113,85,111,123,113,118,89$

Subject No. $1-2-3-4-6-7-8-9-10-11-13$ F-14-15-16-17- 18

Sample Size

Maximum

Minimum

Range

Mean

Variance

Standard Deviation

Mean Deviation

Median

Mode
$-16$

$-129$

$-85$

$-44$

- 111.13

$-172.25$

$-13.12$

$-10.6$

$-113$

$-113 \quad 118 \quad 123$

Note - These are [.Q. scores not related to percentages for comparison in this chart.

F* - Not significant - subject has language problem resulting in a score closely related to mental retardation and it was therefore necessary to discover persons identity to help validate this test pattern.

Note - Subject numbers 5 and 12 were not selected by students involved in this experiment. 
Analysis of Variance of the Means of Total Responses to Differential Aptitude Test - Booklet '2' - Form ' L' Space Relations

Scores $\quad 80,37,65,78,55,57,85,85,13,57,58,48,91,73,77,37$

Subject No. $1-2-3-4-6-7-8-9-10$ F-11 - $13-14-15-16-17-18$

Sàmple Size

Maximum

Minimum

Range

Mean

Variance

Standard Deviation

Mean Deviation

Median

Mode
$-16$

$-91$

$-13$

$-78$

$-62.25$

$-453$

$-21.28$

$-17$

$-61.5$

$-37 \quad 57 \quad 85$

Note - This test was evaluated on raw score only and converted to percentages out of 100 for purposes of comparison.

F* - Not significant - subject has cultural problem which relates back to previous data collected by others and it was therefore necessary to discover person's identity to help validate test pattern.

Note - Subject Numbers 5 and 12 were not selected by subjects involved in this experiment. 
Analysis of Variance of the Means of Total Responses to Creativity Test Part of O.C.A. Entrance Test

Scores

$60,52,20,84,36,60,68,68,52,52,52,68,52,68,36,44$

Subject No. $1-2-3-4-6-7-8-9-10-11-13-14-15-16-17-18$

$\begin{array}{lll}\text { Sample Size } & -16 & \text { No Previous Experience with test }-16 \\ \text { Maximum } & -84 & \\ \text { Minimum } & -20 & \\ \text { Range } & -64 & \\ \text { Mean } & -54.5 & \\ \text { Variance } & -245.06 \\ \text { Standard Deviation } & -15.65 \\ \text { Mean Deviation } & -11.81 \\ \text { Median } & -52 & \\ \text { Mode } & -52\end{array}$

Note - This test was evaluated on a point system of 1 to 10 or 1 to 5 based on neatness, originality, and completeness and converted to percentages out of 100 for comparison.

Note - Subject numbers 5 and 12 were not selected by students involved in this experiment. 
Comparisons of Means of the Generalization

Gradients (I.Q. - Creativity)

Scores $89,77,59,106.5,69.5,82.5,94.5,97.5,87.5,82.5,68.5,89.5,87.5,90.5,77,67$

Subject $1-2-3-4-6-7-8-9-10-11-13-14-15-16-17-18$

No.

Sample Size

Maximum

Minimum

Range

Mean

Variance

Standard Deviation

Mean Deviation

Median

Mode
$-16$

$-106.5$

$-59$

$-47.5$

$-82.8$

$-157.76$

- 12.55

$-9.97$

$-85$

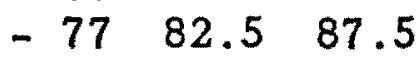

Note - This table indicates the average score from a combined evaluation. of the mental ability test and the creativity test, which the computer selected as being the most significant comparable set of factors. 


\section{SUMMARY OF RESULTS}

Table 4* shows that there were no significantly comparable factors between I.Q. tests and space relations tests, or creativity tests and space relations tests, but as shown in Table 4 there was some significance between I.Q. abilities and creative abilities which was transferred into gradients running from 106.5 to 59 .

Figure 2 - 'Subject Selection Chart' shows how subjects were chosen at random in matched pairs as follows:

\section{Experimental Group}

Subject

Subject

Median

Subject

Subject
6

7

14

15

\section{Control Group}

2

Il

16

17

To arrive at the above selection the matched pairs were each given an alphabetical letter and drawn by a random selection to see which would be the control group and which would be the experimental group.

I.Q. Test results proved that the majority of students had average mental ability; no exceptionally high aptitudes in this test became apparent. The low figure out of sixteen subjects was identified as subject \#13 and further investigation led to the fact that the subject was of foreign extraction and has had language communication problems in the past.

Given equal areas under the respective mean generalization gradients, in order to test for differences in ability among the gradients, the number of responses to the modal stimulus $\left(0^{\circ}\right)$ for each $\underline{S}$ was subjected to a square-root transformation and an analysis of variance was done. 


\section{SUMMARY OF RESULTS (continued)}

The constant factor of significance here is that the highest I.Q. rating was also the highest rating on the Creativity Test and ranked 5th.highest in the Space Relations Test. In contrast, the lowest ranked I.Q. rating (other than that mentioned above) also was the lowest ranked on the Space Relations Test and the 4th.lowest on the Creativity Test. Space Relations Test results show rather spasmodic consistency between I.Q. and Creativity Tests; except at the top and bottom of the rankings, there were proximities that could be followed. The low figure out of sixteen subjects was identified as subject \#10 on these tests; further investigation led to the fact that this subject had taken the I.Q. test before and had achieved a similar result. This student is also of foreign extraction and has difficulty with cultural variations in his new environment.

The Creativity Test results must be weighed against the fact that of all three tests, it is the only one with potential subjective marking values; however, the rate of failure was identical to that of the Space Relations Test, even though only one subject failed both; he also happened to be the subject with the lowest I.Q. ranking, other than the problem subject \#13 mentioned above.

In summing up this comparison, the constant factor of a $5 \%$ variation between subjects in both the Creativity Test and the Space Relations Test evaluations was 5 subjects or $30.3 \%$ of the total subjects. 
SUMMARY OF RESULTS (continued)

The experimental subjects were contacted on November 24th,1972, and asked to reply by mail to the author, asking for their permission and previously related design experiences and if they cared to participate in this project. In conclusion they had all done so, affirming their positive acceptance as of December 8th,1972, which allowed for the major experiment to start January 1973. 


\section{CHAPTER IV}

\section{MAJOR METHODS \& BALANCE OF PROGRAMME}

Procedures \& Methods:

Experimental subjects were put through a series of job functions in and for the offices of William Kilborn Associates on Wednesdays during the months of January, February and part of March 1973. These functions included: commercial planning, colour schedules, client contact during the research and analysis period, product research, filing system updating and cost analysis reports. Skills required included drafting, colour selection, custom designing and report writing.

Each subject worked a minimum of two Wednesdays and two Saturdays, to simulate as closely as possible the equivalent of a forty hour week. Interviews with each subject were taped prior to their starting and then upon completion of their work load, to obtain their first-hand reaction; and for purposes of comparison.

Job Functions. \& Results:

The four experimental subjects completed their 'work term' assignments by March 17,1973, during which time their functions were divided into internal projects and diversified external projects with the following observations: Internal Projects: (completed by all subjects)

i) new catalogue research and filing - 3 hours.

ii) assistance in specification filing system - 3 hours.

- Total Internal Time -6 hours.

External Projects: (varied with each subject)

Subject \#14 - Work dates: Jan.24,25,27 and Feb.3/73 - Total 34 hours

i) Test Result - Above mean average

ii) Project - Art Selection and written report - K-W Record Project;

A selection of 36 pieces.

iii) Functions - Internal Research - 8 hours External Research - 12 hours, job site \& galleries Written Reports - 8 hours 
Job Functions, \& Results: (continued)

Subject \#14: (continued)

iv) Observations - A. Working conditions - responsive \& positive

B. Work functions - positive reaction, excellent at communication with suppliers.

C. Responsibility - accepted responsibility with some hesitation.

v) Subject's Comments - Excellent work experience; too bad it is so short!

vi) Experimentor's Comment - Co-operative and an enjoyable work relationship.

Subject \#6 - Work dates: Feb.7, 11, 12,15, and 18 - Total 34 hours

i) Test Result - Below mean average.

ii) Project - Zone Planning and Partition layouts - K-W City Hall

iii) Functions - 3rd.floor layout - 20 hours 4 th $\&$ 5th floor layouts -8 hours

iv) Observations - A. Working conditions - responsive \& positive.

B. Work functions - fair reactions and poor communication abilities with negative responses to direct orders.

C. Responsibility - accepted responsibility with no hesitation.

v) Subject's Comments - enjoyed work experience, felt time element was hardly adequate

vi) Experimentor's Comments - tends to dawdle and has poor working habits.

Subject \#7 - Work Dates - Feb.21, 24, 28, and March 3/73 - Total 34 hours

i) Test Result - Below mean average.

ii) Project - Design Presentation - Mayor's Offices K-W City Hall

iii) Functions - Material and colour selection - 10 hours (supplicr rescarch) Furniture selcction - 6 hours (in office) Presentation Preparalion 12 hours $(8$ hours at home) 
Job Functions \& Results (continued)

Subject \#7 (continued)

iv) Observations - A. Working Conditions - minimum response \& negative

B. Work Functions - fair reaction, but good communication abilities with good responses to orders.

C. Responsibility - accepted responsibility reluctantly and with much hesitation.

v) Subject's Comments - the experience was of relatively little value because there was no freedom in design selection.

vi) Experimentor's Comments - This subject had the most valuable summer experience of all those involved in this test and was most capable in the completion of functions assigned; although mental outlook dealing with the size, length, and environment in which she was placed; seemed to draw negative reactions from this subject.

Subject \#15 - Work Dates - March 7,10,14, and 17/73 - Total 34 hours.

i) Test Result-Above mean average.

ii) Project - Furniture Saturation Layouts - K-W City Hall.

iii) Functions - 3rd. Floor layout - 14 hours ( 8 hours at home) 4th \& 5th Floor Layouts - 14 hours ( 8 hours at home)

iv) Observations - A. Working Conditions - responsive \& positive.

B. Work functions - positive reaction, excellent at communication with other staff members.

C. Responsibility - accepted with no hesitation, highly capable of working on his own.

v) Subject's Comments - Good work experience, helped sharpen planning abilities and drafting skills.

vi) Experimentor's Comments - Excellent, co-operative subject and an enjoyable work relationship. 
Selection of Outside Subjects:

During the month of March 1973, contacts were made to obtain the subjects for the secondary Control Group. The following criterion were used in selection:

A. All subjects were to be practising designers with approximately three years practical experience or two years academic design school training and one year's practical experience.

B. Four subjects were selected covering the following market spheres wherever possible: institutional, merchandising, domestic and hospitality fields.

The following individuals agreed to co-operate for the purpose of these experiments:

Subject \#5

Male - 24 years of age; Place of Birth, Paris, Ontario. Education - Beal Technical School - London, Ontario.

Experience - 2 years Eaton's Contract

1 year self-employed

Type of Work - Interior Delineator

Subject \#12

Female - 22 years of age; Place of Birth, Denmark.

Education - 2 years Ontario College of Art - Toronto.

Experience - 1 year Eaton's Contract Division.

Type of Work - J unior Designer - Planning and Paste-ups.

Subject \#20

Male - 23 years of age; Place of Birth, Toronto.

Education - Technical High School - Toronto.

Experience - 2 years Allied Towers Merchants.

Type of Wo rk - Drafting, merchandise planning and fixture design. 
Selection of Outside Subjects (continued)

Subject \#24

Female - 21 years of age; Place of Birth - Ontario.

Education - 3 years - Fanshawe College School of Design.

Experience - 1 year Simpsón's Contract Division.

Type of Work - Custodian - in charge of sample room and supplier contact.

The above subjects were tested on Saturday and Sunday, March 31/73 and April lst/73, at my residence under very informal conditions. They all agreed that they would be interested in the results of the test, but preferred that their names be kept out of any publicized report. It should be noted that all subjects seemed to take the tests very lightly with no serious concern on their part; their reactions will be discussed later in this Report.

The Problem Solving Test:

George Sanders and I met on Tuesdays, the 13th, and 20th of February and Fridays the 16th, and 23rd. of the same month and reached a decision on the criteria, construction, methods and procedures for testing and evaluating all subjects involved in the experimental programme.

The criteria for areas of subject analysis were based on educational development expected to date, and on experience gained through field work. The following specific criteria were established:

1) Product Knowledge

2) Problem Solving Ability

3). Decision Making Ability

4) Technical Skills \& Ability

5) Creative Thinking

6) Aesthetic Judgement 
The Problem Solving Test (continued)

To cover the above a four part test was constructed.

Part I Historical Knowledge. See Criteria (1) (3) \& (6) - 20 :minutes

Part II Decision Making. See Criteria (1) (2) (3) (4) \& (6) - 30 minutes

Part III Creative Communication. See Criteria (2) $\&(5)-25$ minutes

Part IV Product Orientation. See Criteria (1) (3) - 15 minutes.

Total Testing Time -90 minutes.

This method of test construction and the questions asked were left to members of the staff who, with the exception of Mr.Sanders, had no previous knowledge of the criteria or hypotheses of the experiment. Mr. Sanders instructed other staff members in the material to be covered and the length of each part of the test. Responsibilities were assigned as follows: Part I Mr.George Sanders Part II Mr.John Kitamura Part III Mr.Andrew Vasilevich Part IV Mr.William Vine

This writer was given the problem solving test material on the morning of Wednesday, March 28th,1973; at that time, this author was to conduct a regularly scheduled class for third year Interior Design students. The tests were in four separate envelopes to be administered in numerical order. Each test 'part' was then sealed in its envelope and collected before the student proceeded to the next part. The writer, had no knowledge of the actual content of each component prior to testing procedures beginning. The students were neither informed nor made aware of the purpose of the tests at the time, although the experimental subjects were to some degree 
The Problem Solving Test (continued)

aware that these tests were a follow-up of projects completed under my supervision outside of the school curriculum. The blank envelopes which contained their names and tests number to be used again as identification were returned to the student, this procedure was previously discussed under 'Chapter II Method'. New envelopes were distributed to two new subjects outside of the control and experimental groups, so that no student could tell which was a control subject. Two students who had taken the selection tests were not present; therefore the same number of students were in attendance for this test as previously noted in November 1972.

Upon completion of the test all students were informed of its purpose along with that of previous tests. The test information was to be strictly confidential and not to be used in any manner as to their present or future assessment while at Ryerson. At this time the students asked no questions as to personal feedback.

. In addition to the aforementioned problem solving test, a personality Test \#16PF was given to the students which they were asked to take home, complete, and return to the staff office the following day for Mr.G.Sanders and the counselling department of the Institute to examine in conjunction with these findings. 
The Problem Solving Test (continued)

The evaluation of all component parts was as follows:

Part I Percentage - G.Sanders, Wm.Kilborn

Part II Percentage - G.Sanders, Wm.Kilborn

Part III Written Rank Evaluation - G.Sanders, A.Vasilevich

Part IV Percentage - G.Sanders, B.Vine

All test results, charts and graphs, therefore follow these criteria as established by G.Sanders and R. Taber of our counselling department. Observations:

This test occurred during a very crucial time period in the development of the students year-end work. Although they were co-operative, it should be noted that it was given under studio conditions, within school hours between 11:30 and 1 o'clock in the afternoon. The students' attitudes and mental condition were observed to be considerably less attentive than when the students were previously tested in November 1972 under studio condition.

In comparison, the secondary control group selected for this test were much more relaxed and less tense during the test period; they were also asked to complete Test \#16PF at home and return it to the writer. Other Methods Under Study Hypotheses Part B:

The academic standing of the experimental group will not deteriorate compared to the academic standing of the student control group. To arrive at a conclusion it was necessary to evaluate the standings of both control and experimental groups, first in the Fall term December 1972 before the 
Other Methods Under Study Hypotheses Part B (continued) .

experiment took place; and secondly in the Winter Term April 1973 after the experiment was completed.

The students were involved in the six courses of which two are considered core courses:

Interior Design II IDN 032 (core)

Design Applications III IDA 033 (core)

Design Communication III IDD 036

Design Development II - IDV 034

History of Design III IDH 037

Bu siness Practise II IDB 038

To arrive at a mean average alphabetical grade for all six courses at the end of each term, the following method was used:

Step I: Conversion $A=4$

$$
\begin{aligned}
& B=3 \\
& C=2 \\
& D=1 \\
& X=0 \\
& +=.5 \text { to each of the above. } \\
& -=.5 \text { from each of the above }
\end{aligned}
$$

Step 2: Core courses carried a double weight; then all evaluations were added and divided by six to arrive at an average grade.

Step 3: The numerical average was then converted back to a letter grade.

With this completed it was necessary for comparison purposes to convert both the Fall and Winter Grade averages of each subject in the control and experimental group to a percentage. However, it should be noted that the low end of a percentage scale was used for Fall Grades 
Other Methods (continued)

and a high end of the same scale for Winter Grades. The reason for this is quite straightforward. The Interior Design Department considers that Winter. Grades of the same value as Fall Grades carry more weight in April than they do in December. Therefore for purposes shown in 'Figure 4 - Subjects Academic Comparison' the following percentage scale was used:
$A+96-100$
A $\quad 86-95$
A- $81-85$
$B+76-80$
B $\quad 71-75$
B - 70
$C+66-68$
C $61-65$
C- 60
$D+56-59$
D $51-55$
D- 50 
Results :

\section{TABLE I}

Analysis of Variance for Means of Test Scores by Treatment Groups Source DF SS MS F

Between Subjects $11 \quad 2785.55$

Treatment $2 \quad 785.95$ 392.97 1.77 222. 18

Subjects Within Groups

Within Subjects

$24 \quad 5289.07$

Tests

$2 \quad 2709.02$

1354.55

10.74

Treatment $\times$ Test

$4 \quad 326.89$

81.72

0.65

Treatment $\times$ Subjects

With Groups

$18 \quad 2253.16$

126.18

TOTAL

$35 \quad 8074.62$

$$
\begin{aligned}
F .05 \text { at } 2+9 D F & =4.26 \\
2+18 D F & =3.55 \\
4+18 D F & =2.93
\end{aligned}
$$

Table I shows the analysis of variance which is a statistical procedure to determine whether the variance sets of dates should be attributed to chance factors or to treatment conditions of subjects. 


\section{TABLE II}

Analysis of Variance of the Means of Total Responses

to Experimental Test Parts I, II, \& IV

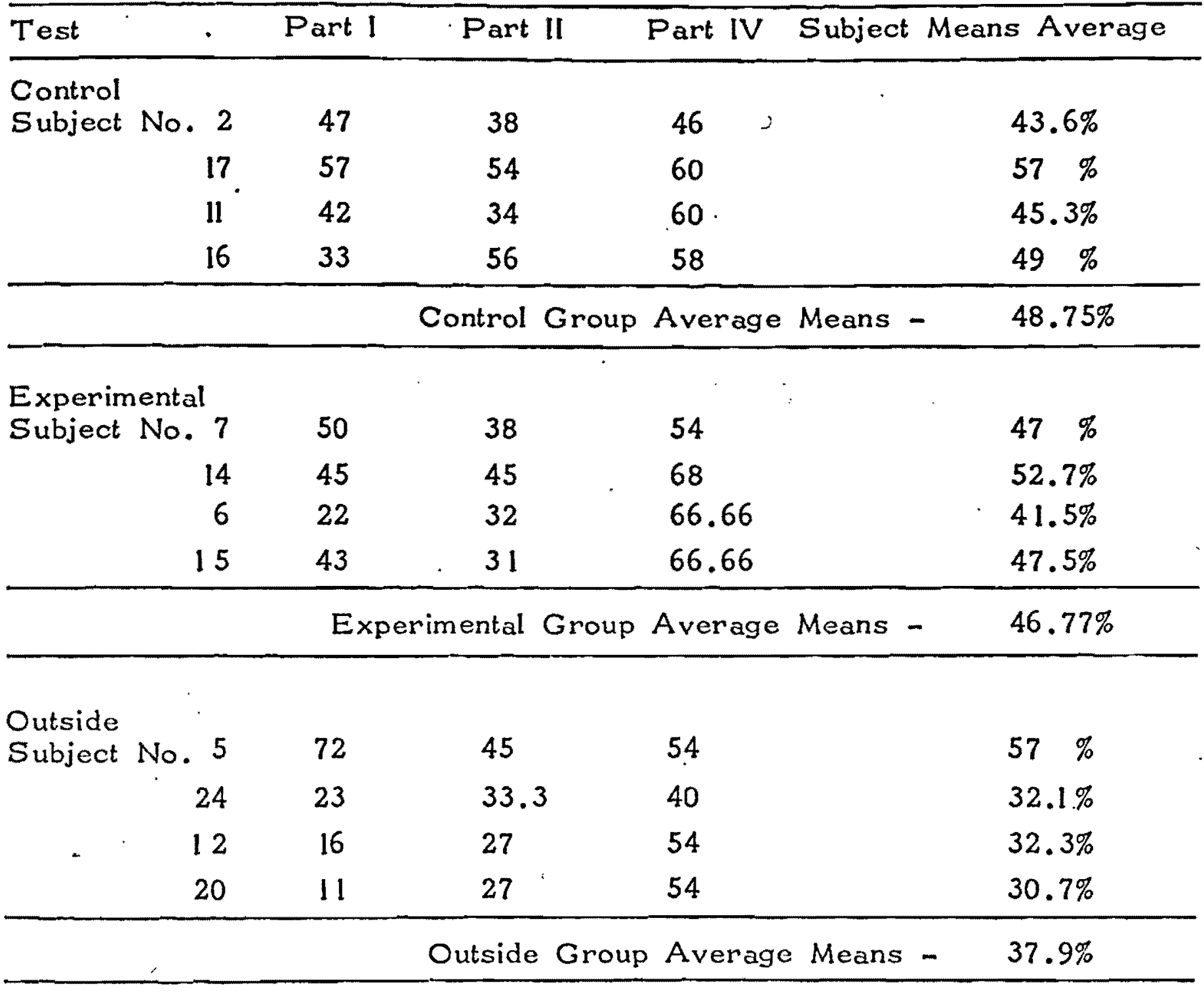


Comparison of The Means of the Generalization Gradients to Part III - Creativity (by rank order)

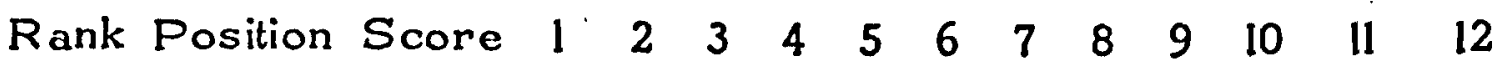
Subject Number $\begin{array}{lllllllllllll}24 & 20 & 11 & 5 & 15 & 12 & 16 & 6 & 14 & 7 & 17 & 2\end{array}$

Sample Size - 20

Conversion Size -12

Inverted Rank Scores - 12 to 1

Maximum - 42

Minimum -10

Range Average - 32

Mean Average -6.5

Control Group Mean - 4.75 (below)

Experimental Group Mean - 5.0 (below)

Outside Group Mean - 9.75 (above)

Standard Deviation - 5

Mean Deviation - 1.75

Median -6.5

Mode -6.3

TABLE III (B)

Analysis of Variance of the Mean Rank for the Three Treatment Groups

\begin{tabular}{lccrl}
\hline Source & DF & SS & MS & F \\
\hline Between'Groups & 2 & 58.5 & 29.25 & 3.11 \\
Within Groups & 9 & 84.5 & 9.39 & \\
\hline
\end{tabular}

TOTAL $\quad 11 \quad 143.0$ -

$F \cdot 05$ at $2+9 D F=4.26$ 
TABLE IV

Comparison of the Means Average Course Assessment Between Fall Term and Winter Term(students only)

Group Subject No. Fall Term Winter Term Subject \% Variation

\begin{tabular}{lrrrr}
\hline Control & 2 & 62 & 72 & $10 \%$ Increase \\
& 17 & 71 & 79 & $8 \%$ Increase \\
& 11 & 62 & 64 & $2 \%$ Increase \\
16 & 70 & 80 & $10 \%$ Increase \\
\hline
\end{tabular}

Control Group Average Means Increase $7.5 \%$

Experimental

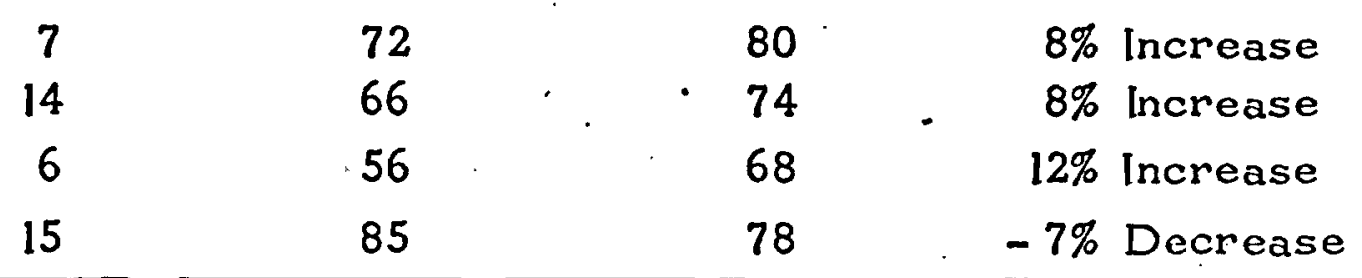

Experimental Group Average Means Increase $5.25 \%$

Note: All data collected for Winter Term Means Average per subject is based on an estimated $15.75 \%$ chance of variation per subjects since the data was collected April 12th/73 not April 23rd/73 when final grades were due.

Results :

i) As Tablel shows, an analysis of variance of groups mean revealed no significant difference among the treatment groups.

ii) There were significant differences among the three test results as shown in 'Table II' and 'Figure 5 !. 
Results: (continued)

iii) The Creativity Test III could not be included in a Computer Analysis of Variance because its method of assessment varied significantly from the other tests given (See Chapter IV Methods)

iv) The Creativity Test III given control and experimental students was compared to an earlier measure of creativity (See Chapter III) and proved to be insignificant as shown on 'Figure 3 Creativity Tests'.

v) Outside subjects did not score better on Test III - Creativity than students as shown on 'Table III (B)'.

vi) Although between the experimental and control group, differences were not significant, it should be noted that the two student groups did score better on three out of four measures than the secondary control group as shown on 'Table II and Figure 5.'

vii) Experimental students did not suffer deterioration in academic design standing compared with control students, but they did not show as great an overall improvement as control students as shown. See Table IV and Figure 4.

viii) The Test \#16PF given experimental and control students measured 16 factors of their personality and ability with five of these factors particularly distinctive of artists. The student experimental and control groups did not differ significantly in the five factors distinctive of artists.

ix) The only statisically significant difference between control students and experimental students on Test \#16PF was in the $Q^{\prime}$ factor which described their liberal or free thinking abilities. The control group scored higher in the $d$ factor than the experimental group. 
Results: (continued)

x) Test \#16PF did show several trends developing in variation between the student experimental group and the student control group as follows:

A) The ' $F$ ' factor which measured the extravert or impulsive part of the personality tended to place the experimental group slightly ahead of the control group.

B) The ' $O$ ' factor which measured the apprehensive or selfreproaching part of the personality tended to place the control group slightly higher in this factor than the experimental group.

xi) The secondary control group did not participate as a group in Test \#16PF and therefore a significant comparison between this group and the two student groups was not possible.

Discussion:

We have now come to the end of these experiments and testing but I have yet to discuss the reasons for their failures and potentialities. I will now try to summarize some of the results which have come from my classroom tests and the experiences I had in individual and group experiments.

- As for hypothesis ' $A$ ' Chapter I, its insignificance as shown under results item (i), may be due to several factors. First, the novelty and the strangeness of the working environment for three out of four experimental students who possibly required time to adapt to this new working condition. The time for their practical training outside the school environment may have been too short to make a significant difference in the values tested. I therefore would recommend a longer work period, equivalent to a co-operative systems work term of perhaps the full school term, as reported in the next Chapter. 
Discussion: (continued)

Secondly, each function performed during the work experience was relatively short, in comparison to the time needed to acquire a skill at that function. Perhaps the question should be asked, 'might it be wise to limit experiences in apprenticeship systems to certain applicable skills required only for business, thus leaving the balance of the student designer's development to the school system?' This, of course, would require another complete study in job functions performed at junior levels in the industry.

The fact that there were significant differences among the test results by each individual subject did not come as a surprise to this writer, as these tests were designed to measure different abilities; and it is a known fact that in a field of artistic endeavour, individuals fortes vary widely dependent upon one's inherent abilities. The disappointment, however, does come in the fact that not only were results with earlier creative testing insignificant for the students; but that there was no direct way to assess this test against a percentage basis arrived at for other tests. It is therefore my recommendation that because of the incompatability between test and the environmental variation as discussed under the design for the second Creativity Test, that measures should be taken to arrive at new methods of assessment for creativity other than those given during this experiment. It would perhaps enhance the value of all tests if outside employers participated in their structuring for future assessment.

Finally, the one encouraging factor here is that students seem to - score better on tests of this nature than do selected outside subjects with equivalent education. This may be due to their familiarity with testing 
Discussion: (continued)

procedures, although each outside subject certainly had proportionately the same academic training as the students. This insignificance seems to be due to the paucity of the sample size. My further investigation would have to represent at least $10 \%$ of the secondary control group classification in the field, perhaps fifty students versus twenty outside subjects. The only realistic difficulty here, is to find that many outside subjects with the qualifications outlined in hypothesis ' $\mathrm{A}$ '

The fact that control and experimental students' personalities did not vary significantly in Test \#16PF is further proof that the methods used for the selection of student experimental and student control subjects, was relatively accurate.

When student experimental subjects scored lower in measures of anxiety and apprehension, as mentioned under item $(x)$ Part B, results; it could possibly be assumed that practical experience in Interior Design may have significantly affected their personalities, because student control subjects have never had practical experience.

The reason for the student control subjects scoring slightly higher on three out of four measures evaluated in the problem solving test of Spring 1973 might possibly be attributed to their significantly higher rating as individuals with the ability to think independently as mentioned under item (ix) results in this chapter. 


\section{Discussion (continued)}

In conclusion although hypothesis ' $A$ ' proved to be insignificant at this time, while hypothesis ' $B$ ' was satisfactory, this does not necessarily disprove hypothesis ' $A$ '. A larger group may be necessary to arrive at a concrete conclusion.

Perhaps in the light of the new developments in education today, a re-examination of the types of experiment given here, and what they measure could lead us to other hypotheses that need to be examined.

Let me now introduce some personal observations and opinions which may seem to be radical.

A. We could do away with examinations that test only recall of facts; they measure only the students' ability to memorize material.

B. We could replace letter or numerical evaluation with verbal evaluation reports.

C. Design education should have a stronger liaison with particular industries in which they wish to place their technically skilled people. - Thus industry could develop these technical skills prior to a student's full accreditation, while educators could proceed with the difficult task of the processes of learning. 


\section{CHAPTER V \\ RECOMMENDATIONS}

\section{SUGGESTED METHOD \& ADVANTAGES OF CO-OP DESIGN:}

As Figure 161 shows it would be necessary to double stream some students at the third year level or even give some of them the option of not participating and graduating in the Spring semester as they do at present.

The reason for double streaming is very basic. A design co-ordinator might make 100 contacts in industry, realistically out of this only $25 \%$ might actually sign contracts with our institute, with perhaps $20 \%$ of these taking more than one student. This would potentially give the Ryerson Interior Design Department a maximum at present of 30 students for whom they could find employment in a given work period.

Who are these potential employers and how do we get them to agree to this programme? The work load for such a programme would have to start in the Fall term the year prior to entering into third year co-op system with the following set of functions and critical path:

A)- The hiring of a 'student co-ordination consultant' with 5 years sales experience and a minimum of 1 year of teaching - September 10th.

B) A Brochure or pamphlet aimed at industry - 500 copies prepared for distribution by - October lst.

C) Personal interviews with prospective co-op employers of which the following list is a sampling of prime prospects.

1. Federal Government - Toronto - 1 student each

- Ottawa - I student each

2. Provincial Government - Toronto - 2 students

3. Simpsons Contract - Toronto - 1 student

4. Eatons Contract - Toronto - 1 student

5. Hudson Bay House - Toronto - 1 student 
C) (continued)

6. Ryerson Physical Plant Dept. - Toronto - 1 student

7. Brian G.Holmes Ltd. - Toronto - 1 student

8. Office Specialty Ltd. - Toronto - 1 student

D) The signing of personnel type contracts completed by April 3lst.

E) The possibility of setting up and running our own staff run design office for those students unable to find jobs through co-op channels to maximum of 5 students, complete and operating by December 31st, prior to first work term.

\section{ADVANTAGES OF DOUBLE STREAMING:}

1. Allows staff to assess better students and put them in the primary or ' $A$ ' $3 r d$. year group by Christmas of 3rd.year.

2. Peak work periods in the interior design business fall into the Winter term and Fall term. This allows us to have our fourth year students available for these periods.

3. All co-op students would graduate together at the end of the summer term allowing them to look for permanent jobs during the peak employment periods in our industry and after the normal summer student has gone back to school.

4. Our graduates in the co-op system would have a minimum of six months working experience plus one year more design and academic training than any other school in the Province.

5. Continual all year round contracts would be available to major co-op supporting design houses.

6. Design companies could use the same students for eight months out of a given year if they wanted to use the students for specific project research.

7. All students would have a minimum of $2-1 / 2$ years design education prior to employment.

8. A continual co-op employer could use two double stream students on the same project, training them over two work periods, and then use their services for the next twelve months, prior to the students graduation, without having a new training programme. 


\section{ADVANTAGES OF DOUBLE STREAMING: (continued)}

9. The institution could justify a summer programme by having a maximum of 3rd. and 4th.year students attending class during the summer session, e.g. 65 out of 70 .

10. Since part-time staff are paid on an hourly basis, this would make for a better use of their time as they are quite often in a better position to teach during a summer semester than during their peak work periods.

11. The weaker students who originally started in Group ' $B$ ' third year would have the opportunity to opt. out of the programme and go back to the standard method for the Fall semester of fourth year after their third year summer work term as shown on Figure 6.

\section{DISADVANTAGES:}

1. Hiring of extra staff to teach primarily fourth year students would be necessary. With only a two year co-op programme, however, minimal increases would be required.

Additional salaries could be partially compensated by the increased potential of funding by industry in such a progiramme. For example, an Interior Design Advisory Council might exact a fee from its supporting co-operative companies who would then have the privilege of making recommendations relative to the University co-operative programme in Interior Design.

2. Alienation and confusion in a student might be increased between industrial practise and academic philosophies.

3. Increased student fees and time in school might cause some to drop the programme. 


\section{SUGGESTED METHOD \& ADVANTAGES OF A STUDENT DESIGN OFFICE:}

\section{RATIONALE:}

Let us consider the following facts:

A. Interior Design is a relatively small profession in Canada with registered memberships in associations across $C$ anada numbering less than 1,000, and possibly another 4,000 calling themselves 'Interior Designers' who are not registered.

B. The average organization employing designers would have no more than three staff members on full-time in this capacity; as taken from the Interior Designers of Ontario membership records.

C. The interior design industry at present is a spasmodic industry in the luxury classification of services.

D. The nature of specific job functions requires personnel who can take projects from their beginning to their end without interruption in the project schedule or in the functions of other personnel.

\section{RECOMMENDATIONS :}

On the basis of this study, our objective and responsibility at Ryerson should be to meet this need, especially with our new level of academic alignment. I therefore recommend that this model design office could be one of the several options to be taken, as soon as it is feasible:

A. I propose a pilot office be established within the contours of the School System with a lead time of two years to develop it to its full extent.

B. Student participation would be a compulsory part of their curriculum during the fall term of their fourth year, or the winter term, or both (See Figure 7).

C. Administration and promotion of this project would be handled by a professional co-ordinator, with students working on actual projects. Their assessment would come from staff observers having no direct connection with the projects.

D. The projects should be non-profit making, allotting funds to the students only for their immediate out-put of time and resources. 
RECOMMENDATIONS: (continued)

E. The sources of projects could be basically governmental at the : Municipal, Provincial or Federal level for a minimum of competition with private industry. Examples of job sources could be:

a) Ryerson Physical Plant Department

b) Ontario Department. of Social \& Family Services - Homes for the Aged Branch, or Department of Health, etc.

c) Interior Design firms who could use these students for back-up

. functions

F. The sources of funds could be two-fold.

a) Grants from Business, Industry and Government

b) Fees of a minimal nature from the client sources.

G. The operation would require separate premises if possible, from the Department but not the Institute, incurring all normal business expenses in the year-round operation.

\section{ADVANTAGES OF A STUDENT DESIGN OFFICE:}

A. Students would acquire practical experience in those skills required by junior designers in the industry.

B. Some supplemental income would become available to students.

C. Summer employment would be provided for third year students who have proven they have the necessary skills to continue but not the funds.

D. Peak work periods in industry fall into Winter and Fall terms; this - allows us to have our fourth year students available for these periods.

E. Continual all year-round drafting, planning and presentation work would be available to interior design firms seeking such a resource service.

F. An increase in teaching staff would not be necessary nor the complicated shifting of teaching terms as shown in the co-operative programme.

G. Increased alienation and confusion in a student between industrial practise and academic philosophies can be controlled and kept to a minimum.

H. No increase in time at school would be incurred as with the co-operative system. 


\section{DISADVANTAGES :}

A. The hiring of a professional co-ordinator, full-time secretary, and advertising promotion would require a budget per annum of approximately $\$ 24,000.00$ which may not be possible to offset by incoming fees. All expenses such as rent, equipment, telephone and other office sundries should be taken care of by fees and profits after the initial year.

B. Increased student fees might possibly be required to offset part of this cost.

C. A realignment of a fourth year programme to include these requirements may prove to be too heavy a load for students in our present system, although three weeks out of twenty-eight minimum should not interfere with the rest of their programme. (S ee Figure 7.) 


\section{SUMMARY}

I wish to present my personal reaction to the study which I have covered in these pages.

I realize increasingly that I am mainly interested in learning what significantly influences behaviour and furthermore that the most vital learning process is self-motivation. When either actual or simulated working conditions can be proven to stimulate this learning process in an institutional environment, then I feel rewarded.

As a consequence, I realize that $\mathrm{I}$ am mainly interested in being a learner, preferably learning things that have some significant influence on my own behaviour. 


\section{BIBLIOGRAPHY}

1. E.L.Homes, "Co-Op Engineering Education", International Journal of Electrical Engineering Education, 1968, Pg.l, 6-9.

2. R.J.Weiser, Advantages of the Co-Operative Engineering Programme at the University of Waterloo for You The Employer. Published U. of W., 1971, Pamphlet. 


\section{VITA AUCTORIS}

1937

Born in Kitchener, Ontario, to Wilfred Earl and Mary Louisa Kilborn.

1950-1955 Attended Sarnia Collegiate Institute and Technical School, Sarnia, Ontario.

1956-1959 Corresponded with I.C.S. Correspondence Institute, Scranton, Ohio, U.S.A. Received Advertising Layout Diploma.

1956-1960 Attended Ontario College of Art; Toronto, Canada, majoring in Interior Design.

1971-1973 Registered as a full-time student in the Department of Interior Design, applied arts division at Ryerson Polytechnical Institute, Toronto, Ontario. 